\title{
Palmas (Arecaceae) útiles en los alrededores de lquitos, Amazonía Peruana
}

\author{
Useful palms (Arecaceae) near Iquitos, Peruvian Amazon
}

\author{
Henrik Balslev¹, César Grandez², Narel Y. Paniagua Zambrana ${ }^{3}$, Anne Louise \\ Møller ${ }^{1}$ y Sandie Lykke Hansen ${ }^{1}$
}

\begin{abstract}
1 Department of Biological Sciences, University of Aarhus, Building 1540, Ny Munkegade, 8000 Aarhus C., Denmark. E-mail Henrik Balslev: henrik.balslev@biology.au.dk

2 Facultad de Ciencias Biológicas, Universidad Nacional de la Amazonía Peruana, Iquitos, Perú.

3 Instituto de Ecología, Universidad Mayor de San Andrés, Casilla 10077-Correo Central, La Paz, Bolivia.

Trabajo presentado al Simposio Internacional "LAS PALMERAS EN EL MARCO DE LA INVESTIGACIÓN PARA EL DESARROLLO EN AMÉRICA DEL SUR", del 07 al 09 de Noviembre 2007, Museo de Historia Natural, Universidad Nacional Mayor de San Marcos, Lima, Perú.
\end{abstract}

Publicado online: 29/11/2008

\begin{abstract}
Resumen
Se presenta información etnobotánica sobre usos de 64 especies de palmas encontradas en 28 comunidades en el Departamento de Loreto, Perú. Las palmas tienen gran importancia como fuente de alimento (Bactris gasipaes, Mauritia flexuosa, Euterpe precatoria, Oenocarpus bataua), para la obtención de fibras (Astrocaryum chambira, Aphandra natalia), en la construcción de viviendas (Euterpe precatoria, Iriartea deltoidea, Socratea exorrhiza), para su techado (muchas especies de Attalea, Lepidocaryum tenue) y para usos medicinales (Euterpe precatoria, Oenocarpus bataua).
\end{abstract}

Palabras clave: etnobotánica, categorías de usos, palmeras, Loreto, Perú

\section{Abstract}

This paper describes the uses of 64 species of palms in 28 villages in Departamento de Loreto, Peru. There, the palms are of great use as food (Bactris gasipaes, Mauritia flexuosa, Euterpe precatoria, Oenocarpus bataua), for fiber production (Astrocaryum chambira, Aphandra natalia), for construction of houses (Euterpe precatoria, Iriartea deltoidea, Socratea exorrhiza), thatching (many species of Attalea, Lepidocaryum tenue) and for many medicinal purposes (Euterpe precatoria, Oenocarpus bataua).

Keywords: ethnobotany, use categories, palm uses, Loreto, Perú

\section{Introducción}

Las palmas son uno de los grupos de plantas económicamente más importantes en el mundo, superado solamente por las gramíneas, las cuales incluyen la mayor parte de las plantas alimenticias anuales, tales como el arroz, el maíz y el trigo. Estas constituyen además un elemento conspicuo e importante en la estructura y ecología de los bosques tropicales, donde debido a su elevada disponibilidad de recursos juegan rol importante proveyendo fuentes de ingresos estables a los pobladores en algunas de las áreas más pobres de estas regiones. Algunas de las características que hacen a las palmas importantes son: 1) incluyen a numerosas especies, 2) son elementos comunes, importantes y diversos de los ecosistemas de bosques húmedos, 3) dominan extensas áreas, particularmente en suelos pobres o mal drenados, 4) incluyen muchas especies que son extremadamente importantes en la dieta de varias especies de vertebrados, 5) son muy importantes para la subsistencia de la población humana y 6) su presencia en el mercado se ha incrementado y es potencial. Por eso conocer las palmas y sus usos es importante para poder comprender cómo los bosques tropicales húmedos y sus varios nichos ecológicos pueden ser utilizados y manejados de manera sostenible.

Las palmas incluyen aproximadamente 700 especies en América del Sur, donde frecuentemente son componentes funcionales clave formando complejos conjuntos que incluyen formas de vida coexistentes, y ocupan todos los niveles del bosque (Kahn, 1991). Las comunidades de palmas son diversas en cuanto a la riqueza local de especies, alcanzando hasta 30-40 especies por hectárea, y en número de tallos (Montúfar y Pintaud, 2006; Vormisto et al., 2004). Su tasa de reemplazamiento ("turnover") en la composición de las especies del bosque es elevada tanto a nivel del microhabitat como a nivel regional, haciéndolas adecuadas para evaluar el impacto del uso humano a través del espacio y el tiempo. Extensas áreas se encuentran dominadas por palmas grandes que crecen en condiciones extremadamente limitantes (Puhakka \& Kalliola, 1993; Kahn \& Mejía, 1990; Macía \& Svenning, 2005; Peters et al., 1989), y producen grandes cantidades de frutos y otros productos valiosos (Kahn, 1988; Peters \& Hammond, 1990). Los frutos de algunas especies de palmas amazónicas abundantes y de amplia distribución, son la fuente principal de alimento para ciertas especies de vertebrados grandes que son la fuente de carne en la zona (Bodmer et al., 1999), y para poblaciones de peces que se alimentan de ellos durante las inundaciones anuales en áreas donde las palmas son dominantes (Goulding, 1980). Los pobladores locales utilizan numerosos productos derivados de las palmas y la mayoría de las especies son importantes localmente para su subsistencia. Algunas especies tienen mayor importancia como fuente de alimento (Bactris gasipaes, Mauritia flexuosa, Euterpe precatoria, Oenocarpus bataua), otras para la obtención de fibras (Astrocaryum chambira, Aphandra natalia), para ser usadas en la construcción (Euterpe precatoria, Iriartea deltoidea, Socratea exorrhiza), el techado (muchas especies de Attalea, Lepidocaryum tenue) y con fines medicinales (Euterpe precatoria, Oenocarpus bataua). Todos estos productos son transportados por los ríos y carreteras hasta los mercados locales (Peters \& Hammond, 1990). La comercialización de los productos derivados de palmas se ha visto incrementada tanto a nivel de los mercados nacionales como de los internacionales, y muchas organizaciones y proyectos tratan de mejorar las condiciones de vida locales promoviendo el procesamiento y la comercialización de estos productos.

La zona de Iquitos en el Perú es una de las más ricas en palmas en la Amazonía y en el neotrópico en general (Bjorholm et al., 2005) y esta riqueza está reflejada en una diversidad correspondiente en los usos de las palmas en la región (Mejía, 1988; Paniagua Zambrana et al., 2007). Varias especies de palmeras forman partes importantes de los sistemas agrarios a lo largo de 
los ríos (Hiraoka, 1985) y entran en la vida cotidiana de todos los que viven en la región. El Aguaje (Mauritia flexuosa) abunda en zonas inundadas y produce frutos comestibles que son apreciados por todos y contribuyen al mantener muchas familias por el ingreso que genera la venta de frutos (Kahn et al., 1993; Padoch, 1988). El mercado de Iquitos es reconocido por su diversidad de frutos y otros productos no maderables, traidos de la selva en los alrededores de la ciudad. En este mercado se comercializan por lo menos 19 especies de palmeras por su frutos comestibles (16 especies), el palmito ( 1 especie), fibras ( 2 especies), hojas (1 especie), aceite (1 especies) y larvas comestibles de insectos que crecen en los estípites de dos especies de palmeras (Mejía, 1992). Otras especies sirven en la construcción de casas, y en Iquitos en particular el uso de Lepidocaryum tenue para techar las casas es preponderante (Kahn \& Mejía, 1987). En toda la región las casas rústicas en las cuales viven la mayoría de la población están construidas con materiales derivados, por lo menos en parte, de varias especies de palmas (Lopez Parodi, 1988). Además las palmeras sirven como materia prima a la producción de un gran número de productos artesanales. Los tallos de la palmera trepadora Desmoncus, usados para canastas y muebles, pueden ser los mas importantes en este sentido (Henderson \& Chavez, 1993; Hübschmann et al., 2007).

Este artículo incluye la lista de especies útiles de palmas que fueron registradas durante expediciones de campo realizadas en los alrededores de Iquitos, Departamento de Loreto, en la Amazonía peruana.

\section{Métodos}

Entre los años 2003 y 2007, visitamos 28 comunidades (Tabla 1, Figura 1 y 2) localizadas en un radio de $350 \mathrm{~km}$ alrededor de Iquitos, donde realizamos observaciones y entrevistamos aproximadamente a 300 personas acerca de los usos de las palmas. La información fue obtenida a través de entrevistas semi-estructuradas con pobladores de diverso origen étnico, incluyendo tanto a los indígenas como a los mestizos. A cada entrevistado se le mostraron las fotografías impresas de las especies de palmas registradas en la zona, una vez reconocida la palma debía ser encontrada en el bosque y posteriormente mostrados todos los productos que obtenían a partir de cada una de ellas.

\section{Resultados}

Se encontró 64 especies de palmas usadas por las pobladores de las 28 comunidades visitados. Entre las 300 personas entrevistados la gran mayoría eran mestizos. Solamente en el caso de las comunidades mas alejados en el río Corrientes nos encontramos con gente que hablaron su idioma nativa, en este caso Urarina, y entonces fue posible registrar los nombres de las palmas usadas en este idioma. Los nombres de la mayoría de las especies siguen la clasificación presentada por Henderson (1995) y Henderson et al. (1995); los nombres de las especies del género Bactris siguen la monografía del género (Henderson, 2000), y un par de especies han sido incluidos en base a publicaciones recientes (Attalea plowmannii en Zona, 2002; Geonoma atrovirens en Borchsenius et al., 2001). La ortografía de los nombres de los autores relacionados a los nombres científicos sigue a Govaerts y Dransfield (2005).

Encontramos una gran variación en cuanto a cuántos y cuáles usos un informante conocía. Esto dependió de la edad, sexo y origen étnico de cada informante, así como de cuánto tiempo habían estado viviendo en la comunidad, existiendo además gran variación entre las comunidades. De hecho, las diferencias en los usos de las palmas entre las comunidades fueron mayores que las encontradas entre cualquier otro factor relacionado a los informantes (edad, sexo, etc.). Esta variación en el conocimiento local de las palmas ha sido analizada en detalle y presentada en otro artículo (Paniagua Zambrana et al. 2007).

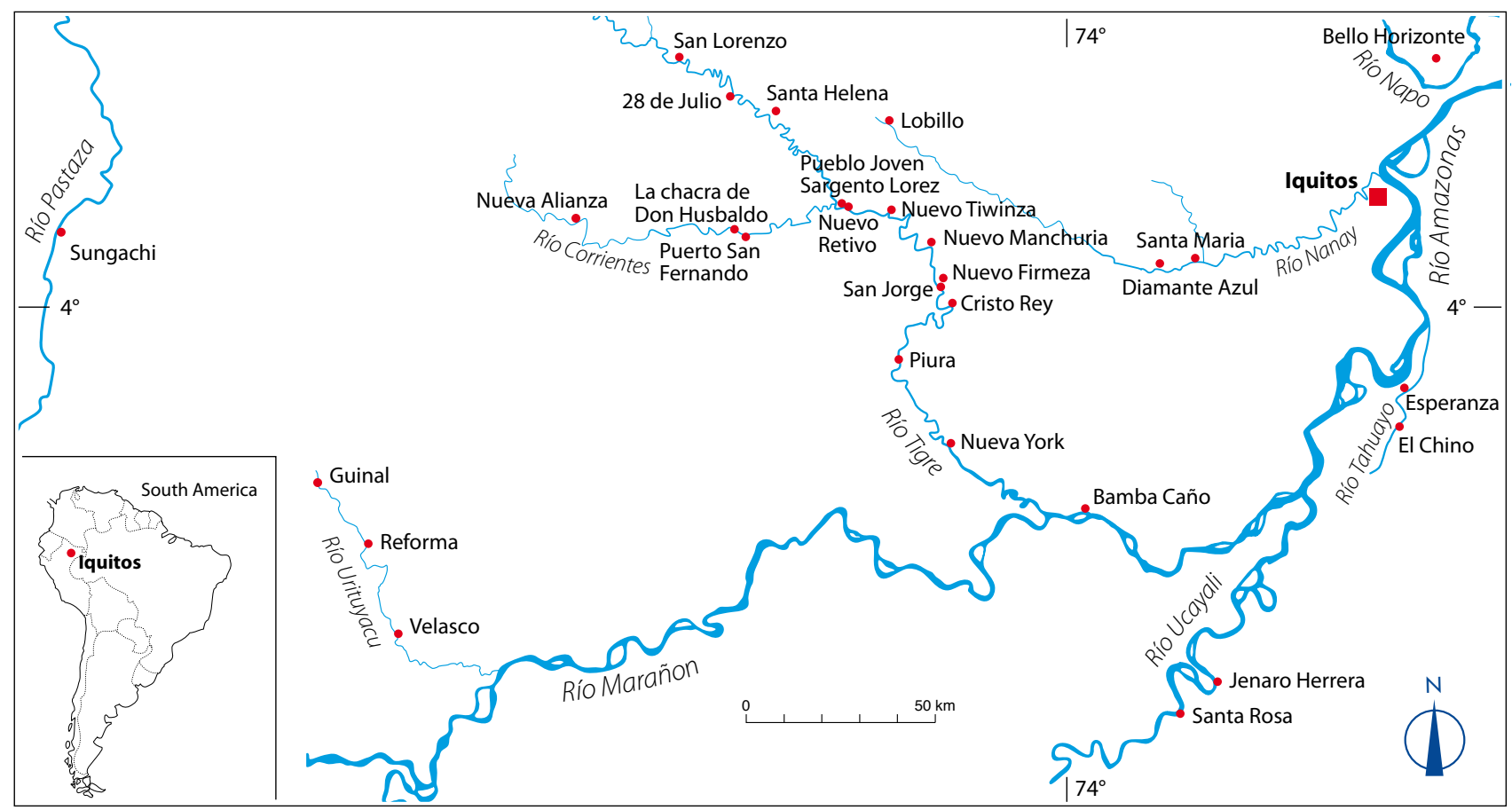

Figura 1. Ubicación de 28 comunidades en los alrededores de lquitos en la Amazonía Peruana, en los cuales se entrevistaron 300 personas sobre sus usos de palmeras. 
Tabla 1. Comunidades en el Departamento de Loreto en la Amazonía de Perú, visitados entre 2003 y 2007 con el propósito de estudiar usos de las palmeras (Arecaceae), indicando en cual río están localizados, y las coordenadas de UTM medido con GPS (todos en sección 18 del sistema UTM).

\begin{tabular}{|c|c|c|c|c|}
\hline & Río & Comunidad & E-W UTM & N-S UTM \\
\hline 1 & Corrientes & Comunidad Nativa Nueva Alianza & 480452 & 9585034 \\
\hline 2 & Corrientes & La chacra de Don Husbaldo & 522275 & 9580640 \\
\hline 3 & Corrientes & Puerto San Fernando & 525105 & 9579162 \\
\hline 4 & Marañon & Bamba Caño & 613588 & 9504720 \\
\hline 5 & Nanay & Diamante Azul & 635434 & 9568620 \\
\hline 6 & Nanay & Lobillo & 564132 & 9608730 \\
\hline 7 & Nanay & Santa Maria & 644697 & 9569906 \\
\hline 8 & Pastaza & Reforma & 422346 & 9500725 \\
\hline 9 & Río Napo & Bello Horizonte & 710385 & 9621339 \\
\hline 10 & Río Tigre & Comunidad Nativa 28 de Julio & 522168 & 9615934 \\
\hline 11 & Río Tigre & Cristo Rey & 579508 & 9559740 \\
\hline 12 & Río Tigre & Nueva York & 578052 & 9522856 \\
\hline 13 & Río Tigre & Nuevo Firmeza & 577254 & 9566430 \\
\hline 14 & Río Tigre & Nuevo Manchuria & 574520 & 9575784 \\
\hline 15 & Río Tigre & Nuevo Retivo & 552426 & 9586024 \\
\hline 16 & Río Tigre & Nuevo Tiwinza & 564018 & 9584886 \\
\hline 17 & Río Tigre & Piura & 565157 & 9545070 \\
\hline 18 & Río Tigre & Pueblo Joven Sargento Lorez & 551030 & 9586826 \\
\hline 19 & Río Tigre & San Jorge & 576616 & 9564026 \\
\hline 20 & Río Tigre & San Lorenzo & 508764 & 9626798 \\
\hline 21 & Río Tigre & Santa Helena & 534161 & 9611712 \\
\hline 22 & Tahuayo & El Chino & 697902 & 9523896 \\
\hline 23 & Tahuayo & Esperanza & 699204 & 9534216 \\
\hline 24 & Ucayali & Jenaro Herrera & 647502 & 9458230 \\
\hline 25 & Ucayali & Santa Rosa & 637416 & 9450172 \\
\hline 26 & Urituyacu & Guineal & 409384 & 9517294 \\
\hline 27 & Urituyacu & Sungachi & 342680 & 9585379 \\
\hline 28 & Urituyacu & Velasco & 429763 & 9476780 \\
\hline
\end{tabular}

\section{Observaciones originales de los usos de palmas}

Aquí, presentamos una descripción cualitativa de nuestras observaciones de todas las diferentes formas en las cuales las palmas son utilizadas en el área de estudio. Las descripciones están organizadas alfabéticamente por especie y bajo seis categorías de uso: 1. Alimenticio, 2. Construcción, 3. Herramientas y utensilios, 4. Medicinal y cosmético, 5. Decorativo y ceremonial, 6. Comercial. También incluimos los nombres comunes reportados por los informantes locales, incluyendo los nombres tanto en castellano como en urarina en los casos cuando eso es relevante. Los números citados bajo la denominación de "Comunidad" corresponden a los números dados a las comunidades visitadas, y descritos en la Tabla 1. Muchas de las especies registradas cuentan con una muestra de herbario, los números de colección se encuentran citados bajo la denominación de "Voucher" representando colecciones hechos por $\mathrm{H}$. Balslev y depositados en los herbarios de la Universidad Nacional de la Amazonia Peruana (AMAZ) y el herbario de la Universidad de Aarhus (AAU). En algunos casos no fue posible colectar muestras en las comunidades donde se realizó las entrevistas. Eso se indica con el texto: "sin muestra colectada”. En estos casos existen muestras colectadas de las mismas especies dentro del área de estudio, pero no en las comunidades visitados en el estudio etnobotánico.

\section{Aphandra natalia (Balslev \& A.Hend.) Barfod}

Español: Piassaba, Chipati. Urarina: Accuedé

Usos: Construcción - Ocasionalmente el tronco es utilizado para los postes (horcones) de las viviendas, y para las vigas del techo y los pisos; las hojas son utilizadas para el techado de las viviendas permanentes y temporales, poco frecuente para cocinas, y en algunos casos son colocadas solamente en los bordes o utilizadas para cubrir la cumba del techo (cumberas). Herramientas y utensilios - Las hojas tiernas son utilizadas en canastos de rápida fabricación que son elaborados para el traslado de frutos o animales muertos desde el bosque; las fibras extraídas de la base de las hojas son utilizadas localmente para la fabricación de escobas; las hojas son también utilizadas para la fabricación del "capillejo" y el "cargajo" (material para empujar los dardos en las cerbatanas), utensilios empleados en la cacería; 
las venas principales de las pinnas - debidamente liberados de sus laminas - son utilizados para extraer las larvas que se desarrollan en los troncos de otras especies. Alimenticio - Los frutos maduros son recolectados y consumidos cocidos, también son utilizados para la elaboración de bebidas; las semillas inmaduras son consumidas; ocasionalmente el palmito es extraído para ser consumido crudo o cocido. Para venta - Las fibras obtenidas de la base de las hojas son ampliamente comercializadas. Comunidad: $1-6,10,12,14,15,19,20,23,27-30$. Voucher: H. Balslev 7434 .

\section{Astrocaryum chambira Burret}

Español: Chambira. Urarina: Disieé

Usos: Medicinal y cosmético - El palmito, los frutos y las raíces son utilizados para la preparación de extractos contra la hepatitis, malaria y la fiebre amarilla; la raíz también sirve contra infecciones. Construcción - Ocasionalmente el tronco es utilizado para los postes (horcones) de las viviendas; las hojas suelen ser utilizadas para el techado de las viviendas, su uso no es frecuente. Herramientas y utensilios - Las hojas tiernas son utilizadas para la obtención de fibras que son utilizadas para la fabricación de abanicos, tapetes (tendidos), bolsas (shilca), hamacas, prendas de vestir, escobas, redes para pesca, también son utilizadas para sellar huecos y rajaduras en las canoas; las espinas son utilizadas como agujas y ocasionalmente en artesanías. Alimenticio - Los frutos maduros son comestibles crudos y utilizados para elaboración de bebidas; el palmito es extraído para ser consumido crudo o cocido; las larvas de coleóptero (suris) que desarrollan en los troncos caídos son cosechadas y consumidas cocidas; las semillas son consumidas crudas como almendras. Para venta - Las cestas, abanicos, tapetes y bolsas fabricadas de las fibras obtenidas de las hojas tiernas son comercializados. Comunidad: 1-30. Voucher: H. Balslev 6641.

\section{Astrocaryum jauari Mart.}

Español: Huiririma. Urarina: Siyaná

Usos: Medicinal y cosmético — El palmito es utilizado para la preparación de extractos contra la hepatitis. Construcción - El tronco es utilizado para los postes (horcones) de las viviendas, menos frecuente es su uso para las vigas de techos y pisos; las hojas suelen ser utilizadas para el techado de las viviendas, entremezcladas con otras más resistentes. Herramientas y utensilios — Las hojas jóvenes son utilizadas para la fabricación de canastos de rápida elaboración en sus visitas al bosque; ocasionalmente las hojas tiernas se usan en la fabricación de abanicos y escobas; los frutos son utilizados como carnada para la pesca. Alimenticio - Los frutos maduros son comestibles y utilizados para la preparación de bebidas; ocasionalmente el palmito es extraído para ser consumido; las larvas de coleóptero (suris) cosechadas de los troncos en descomposición y de los frutos viejos son consumidas cocidas. Comunidad: 1-4, 6, 7, 9-21, 24-30. Voucher: H. Balslev 7347

\section{Astrocaryum murumuru Mart. complejo}

[corresponde a las especies Astrocaryum javarense Trail, $A$. macrocalyx Burret, A. urostachys Burret y A. chonta Mart. reconocidos por Kahn y Millan (1992) y Govaerts y Dransfield (2005). Astrocaryum macrocalyx es muy común en el valle del río
Nanay, hasta el río Tigre al Oeste. Astrocaryum javarense solo se encuentra en el margen sur del río Ucayali y del río Amazonas, $A$. chonta crece en las restingas del río Ucayali, y $A$. urostachys, que se extiende de la Amazonía ecuatoriana a la margen norte del río Marañon, no pasa el río Tigre hacia el este - Kahn, este volumen; Vargas y Pintaud, este volumen].

\section{Español: Huicungo. Urarina: Ajuaá}

Usos: Medicinal y cosmético — El palmito, las raíces y el tronco son utilizados para la elaboración de extractos utilizados contra la hepatitis, fiebre y la malaria; el palmito también es utilizado como cataplasma para dolores de espalda; la corteza sirve contra la fiebre. Construcción - El tronco de los individuos adultos es utilizado para los postes (horcones) de las viviendas, ocasionalmente para vigas en los techos y cercos en campos de cultivos; la madera es empleada en la fabricación de los pisos y paredes de las viviendas; las hojas suelen ser utilizadas para el techado de las viviendas y en viviendas temporales, entremezcladas con hojas mas resistentes. Herramientas y utensilios - Ocasionalmente las hojas tiernas son utilizadas para canastos de fabricación rápida cuando acuden al monte en busca de frutos o a cazar; una persona reportó el uso del palmito como cebo para pescar. Alimenticio Los frutos maduros son comestibles; el palmito ocasionalmente es consumido; las larvas de coleóptero (suris) cosechadas de los troncos en descomposición y de los frutos viejos son consumidas cocidas. Comunidad: 1-7, 9-30. Voucher: H. Balslev 7530.

\section{Attalea butyracea (Mutis ex L.f.) Wess.Boer}

Español: Sheebon, Shebon, Shapaja. Urarina: Seedí, Ej Lele

Usos: Medicinal y cosmético — Las raíces son utilizadas en la elaboración de extractos utilizados contra la hepatitis. Construcción - Los troncos son ocasionalmente utilizados para los postes (horcones) de las viviendas, y la madera en las paredes; las hojas son utilizadas para el techado de viviendas, para su colocación solo en los bordes y/o en la cumba. Herramientas y utensilios Las hojas jóvenes son utilizadas en la fabricación de abanicos, canastos, esteras y algunas veces para la fabricación de escobas; las larvas (suris) que son cosechadas de troncos caídos o de frutos viejos, son utilizadas como carnadas en la pesca; la madera podrida del tronco caído sirve como fertilizante para otras plantas. Alimenticio - Los frutos maduros son comestibles y consumidos crudos, cocidos son utilizados para la preparación de bebidas; el palmito es extraído para ser consumido; las semillas son colectadas para ser consumidas como almendras crudas o tostadas al fuego; las larvas de coleóptero (suris) cosechadas de los troncos en descomposición y de los frutos viejos son consumidas cocidas. Comunidad: 1-16, 18-30. Voucher: H. Balslev 6575.

\section{Attalea insignis (Mart.) Drude}

\section{Espańol: Shapaja, Shebon}

Usos: Medicinal y cosmético — Las raíces son usadas con fines medicinales. Construcción - Las hojas sirven para el techado de las viviendas. Herramientas y utensilios - El pecíolo de las hojas se utiliza para hacer dardos que se usan para matar animales. Alimenticio - Los frutos maduros son comestibles; las larvas de coleóptero (suris) cosechadas de los troncos en descomposición y los frutos viejos son consumidas cocidas. Comunidad: 1,2 , 4, 6-9, 12-27. Voucher: H. Balslev 7104. 


\section{Attalea maripa (Aubl.) Mart.}

Espańol: Inayuga

Usos: Medicinal y cosmético — El palmito es utilizado para la preparación de un extracto utilizado contra la hepatitis; la raíz tiene un amplio uso medicinal; los frutos sirven contra la diarrea. Construcción - Las hojas son utilizadas en el techado de viviendas permanentes entremezcladas con la hojas de otras especies, y para viviendas temporales. Herramientas y utensilios — Las hojas tiernas son utilizadas para la fabricación de abanicos o canastos de rápida fabricación en el bosque; también son utilizadas para rellenar las cerbatanas; el pecíolo de las pinnas es usado para la fabricación de dardos y cerbatanas. Alimenticio - Los frutos maduros ocasionalmente son recolectado y consumidos; el palmito es comestible; las larvas de coleóptero (suris) suelen ser cosechadas de troncos caídos y consumidas cocidas. Comunidad: 3, 6, 7, 9, 11, 12, 15, 17, 20, 22-27, 29, 30. Voucher: sin muestra colectada.

\section{Attalea microcarpa Mart.}

Español: Shapaja, Katirina, Shebon

Usos: Construcción — Las hojas se utilizan en los techos de viviendas permanentes y temporales. Alimenticio - Los frutos maduros son comestibles. Comunidad: 1, 4, 6-9, 12-27. Voucher: H. Balslev 7315.

\section{Attalea phalerata Mart.}

Español: Shapaja. Urarina: Seedí, Ej Lele

Usos: Medicinal y cosmético - El aceite obtenido de los frutos y las semillas es utilizado con fines medicinales. Construcción - El tronco es utilizado para los postes (horcones) de las viviendas; las hojas son utilizadas en los techos de las viviendas. Herramientas y utensilios - Las hojas tiernas son utilizadas en la fabricación de canastos, abanicos, sombreros y escobas; las larvas de coleóptero (suris) que se desarrollan en los frutos viejos y en los troncos caídos son utilizadas como carnada en la pesca. Decorativo y religioso - Ocasionalmente las hojas son utilizadas con fines decorativos en eventos festivos. Alimenticio - Los frutos maduros son colectados para ser consumidos crudos; el palmito es extraído y consumido crudo o cocido; las semillas son colectadas y consumidas como almendras crudas o cocidas al fuego; las larvas (suris) que desarrollan en los troncos en descomposición suelen ser cosechadas para ser consumidas cocidas. Comunidad:1-10, 12-30. Voucher: H. Balslev 6581.

\section{Attalea plowmanii (Glassman) Zona}

Español: Shapaja

Usos: Construcción - Las hojas se utilizan en los techos de viviendas permanentes y temporales. Alimenticio — Los frutos son comestibles; ocasionalmente el palmito es colectado y consumido. Comunidad: 1, 4, 6-9, 12-16, 18-26, 29. Voucher: sin muestra colectada.

\section{Attalea racemosa Spruce}

Español: Shapaja

Usos: Construcción - Se utilizan las hojas para techados de viviendas permanentes y temporales. Herramientas y utensilios - Las larvas (suris) que se desarrollan en los frutos viejos ocasionalmente se utilizan como cebo de pesca. Alimenticio - Los frutos son comestibles; ocasionalmente el palmito es comestible. Comunidad: 1, 4, 6-9, 12-27. Voucher: H. Balslev 7453.

\section{Bactris acanthocarpa Mart.}

Español: Ñeja, Nejilla, Chontilla

Usos: Medicinal y cosmético — La raíz sirve contra la malaria. Construcción - Ocasionalmente el tallo es utilizado para las vigas de los pisos. Alimenticio - Los frutos maduros son comestibles. Comunidad: 1, 2, 4, 6, 7, 9, 11-15, 19, 20, 22-26, 30. Voucher: H. Balslev 7288 .

\section{Bactris bidentula Spruce}

Español: Nejilla,

Usos: Herramientas y utensilios - Ocasionalmente los frutos son utilizados como cebo para pescar. Alimenticio - Los frutos maduros son comestibles. Comunidad: 4, 6, 7, 9, 12-16, 19, 20, 23-25, 27. Voucher: H. Balslev 7517.

\section{Bactris bifida Mart.}

\section{Español: Nejilla, Neja negra}

Usos: Alimenticio - Los frutos maduros son comestibles. Comunidad: 1, 3, 4, 6, 7, 9, 12-16, 18-21, 23-27. Voucher: H. Balslev 6604 .

\section{Bactris brongniartii Mart.}

Español: Nejilla

Usos: Herramientas y utensilios - Los frutos son utilizados como carnada en la pesca. Alimenticio - Los frutos maduros son comestibles. Comunidad: 1, 6, 7, 9, 11-16, 18-21, 23-27. Voucher: H. Balslev 7516.

\section{Bactris concinna Mart.}

Espańol: Nejilla de la altura, Chontilla, Nejilla. Urarina: Atanaií

Usos: Construcción - Los tallos con utilizados para las vigas de los techos y como postes en los cercos; las hojas son empleadas para el techado de las viviendas permanentes y temporales. Herramientas y utensilios — Los tallos son utilizados para tablas utilizadas como plataformas en las canoas. Alimenticio - Los frutos maduros son comestibles. Comunidad: 5-10, 12-16, 19, 23-27, 29, 30. Voucher: sin muestra colectada.

\section{Bactris corossilla H.Karst.}

Español: Nejilla, Chundilla. Urarina: Atanaií

Usos: Construcción - Las hojas son usadas para techado en viviendas temporales. Alimenticio - Los frutos maduros son comestibles. Comunidad: 3. Voucher: H. Balslev 7294.

\section{Bactris gasipaes Kunth}

Español: Pijuayo, Chunda. Urarina: Dijié 
Usos: Medicinal y cosmético — La raíces son utilizadas para la preparación de un extracto usado contra la hepatitis, dolor del estómago, malaria y como fertilizante para las mujeres; las raíces fueron también reportadas como venenosas y abortivas, pero probablemente depende de la manera de preparación; se usa también un extracto de las raíces para obtener un pelo más brillante y fuerte; las mujeres comen los frutos cocidos para promover la producción de leche durante la lactancia; la raíz también se utiliza contra enfermedades en animales. Construcción - Los troncos son utilizados como postes (horcones) en las viviendas y en cercos de campos de cultivo, también son usados para vigas en techo y pisos, y ocasionalmente como madera para pisos y paredes; menos frecuente es el uso de las hojas para el techado de viviendas. Herramientas y utensilios - Los troncos son utilizados para la fabricación de cerbatanas, utensilio empleado para la cacería; la madera dura es también utilizada para fabricar anzuelos, arcos de flechas; las hojas tiernas se utilizan para la obtención de fibras; y las hojas maduras suelen ser utilizadas para rellenar las cerbatanas. Decorativo y religioso - Ocasionalmente las hojas son cortadas con fines decorativos en eventos festivos o religiosos. Alimenticio - Los frutos maduros son comestibles cocidos y utilizados para la fabricación de bebidas (chicha); el palmito es comestible y muy apreciado en la región; ocasionalmente las larvas de coleóptero (suris) que se desarrollan en los troncos caídos son cosechadas y consumidas cocidas; tanto los frutos como las semillas son utilizados para la extracción de aceites. Para venta - El aceite extraído de las semillas en comercializado en los poblados más grandes; la semillas son recolectadas y seleccionadas para comercializarlas con fines de producción (plantaciones); los frutos son comercializados (5 soles cada racimo). Comunidad:1-4, 6-30. Voucher: sin muestra colectada.

\section{Bactris halmoorei A.J.Hend.}

\section{Espańol: Nejilla}

Usos: Construcción - Los troncos son ocasionalmente utilizados en la construcción de viviendas, para vigas de techo y pisos. Herramientas y utensilios - Ocasionalmente los frutos son utilizados como cebo para la pesca. Alimenticio - Los frutos maduros son comestibles. Comunidad: 2, 4, 6, 7, 12, 14, 16, 19, 21, 24, 25. Voucher: sin muestra colectada.

\section{Bactris hirta Mart. var. hirta y var. lakoi (Burret) A.J.Hend}

\section{Español: Nejilla}

Usos: Alimenticio - Los frutos maduros son comestibles. Comunidad: 4, 6, 9, 12, 14, 16, 19, 23-26. Voucher: H. Balslev 7307.

\section{Bactris macroacantha Mart.}

\section{Español: Nejilla}

Usos: Alimenticio - Los frutos maduros son comestibles. Comunidad: 1, 4, 6, 7, 9, 12-16, 19-21, 23-25, 27. Voucher: H. Balslev 7536 .

\section{Bactris maraja Mart.}

Español: Dinamillo de la altura, Nejilla. Urarina: Dijié
Usos: Alimenticio - Los frutos maduros son comestibles. Comunidad: 3, 4, 6, 7, 9-16, 19-30. Voucher: H. Balslev 7459 .

\section{Bactris riparia Mart.}

Español: Nejilla, Chontilla

Usos: Medicinal y cosmético — La raíz se utiliza para alteraciones de la menstruación. Herramientas y utensilios - Ocasionalmente los frutos son utilizados como cebo para pescar o como balas en la caza de animales. Alimenticio - Los frutos maduros son comestibles. Comunidad: 6, 7, 11, 13, 14, 19, 20, 23, 25-27. Voucher: sin muestra colectada.

\section{Bactris schultesii (L.H.Bailey) Glassman}

\section{Español: Nejilla}

Usos: Construcción - En algunos casos se utilizan las hojas en los techos de viviendas. Alimenticio - Ocasionalmente los frutos maduros son comestibles. Comunidad: 4, 6, 13-15, 19, 21, 23, 25. Voucher: H. Balslev 7512 .

\section{Bactris simplicifrons Mart.}

Español: Nejilla, Chondilla

Usos: Medicinal y cosmético - Se utilizan los frutos contra la fiebre. Construcción - Ocasionalmente se usan las hojas en los techos de viviendas. Alimenticio - Ocasionalmente los frutos maduros son comestibles. Comunidad: 4, 7, 11, 12, 14, 19, 22, 25, 27. Voucher: H. Balslev 7100 .

\section{Chamaedorea pauciflora Mart.}

Español: Ponilla, Sangapilla

Usos: Medicinal y cosmético - Una persona mencionó que la flor tiene una fragancia agradable y sirve como desodorante. Construcción - Ocasionalmente se utilizan las hojas en los techos de viviendas. Herramientas y utensilios - En algunos casos se utiliza la raíz como escoba; los frutos maduros son usados como colorante de textiles. Alimenticio - Ocasionalmente los frutos maduros son comestibles; las hojas se utilizan para envolver alimentos. Comunidad: 7, 9, 12, 14, 16, 19, 20, 22, 24, 25, 27. Voucher: $\underline{H}$. Balslev 7389.

\section{Chamaedorea pinnatifrons (Jacq.) Oerst.}

Español: Casha ponilla, Ponilla, Chontilla. Urarina: Eichú

Usos: Construcción - Se utilizan las hojas en los techos de las viviendas y el tallo para viviendas también. Herramientas y utensilios - En algunos casos se utiliza la raíz como escoba y el tallo para herramientas; también se hacen ratoneras de los tallos; los frutos sirven como cebo para pescar y como cuentas en artesanías. Alimenticio - Los frutos maduros son comestibles. Para venta - Se venden los frutos para comer y las semillas para collares. Comunidad: 3, 5, 7-16, 19-22, 24-30. Voucher: $H$. Balslev 6664.

\section{Chelyocarpus repens F.Kahn \& K.Mejia}

Español: (Falso) Bombonaje 
Usos: Construcción — Las hojas son utilizadas en los techos de las viviendas. Herramientas y utensilios - Se utilizan las hojas como paraguas, sombreros y cestas. Alimenticio - Ocasionalmente los frutos maduros son comestibles. Comunidad: 1, 4, 6, 7, 9, 12, 14-17, 19-17. Voucher: sin muestra colectada.

\section{Chelyocarpus ulei Dammer}

Espańol: Sacha aguajillo

Usos: Herramientas y utensilios - Las hojas tiernas son empleadas en la fabricación de abanicos. Alimenticio - Ocasionalmente los frutos maduros son comestibles. Comunidad: 3, 5. Voucher: H. Balslev 7403.

\section{Cocos nucifera L.}

Español: Coco

Usos: Medicinal y cosmético — Ocasionalmente los frutos son utilizados contra las hemorroides; la cáscara seca de los frutos se ralla y utiliza contra malaria y pulmonía; la leche es buena para el parto, contra la fiebre y malaria. Construcción - El uso del tronco para postes (horcones) y las hojas para el techo de las viviendas permanentes y temporales es muy poco frecuente. Alimenticio - El endosperma líquido del fruto es una de las bebidas más apetecidas. Para venta - Los frutos son comercializados ocasionalmente. Comunidad: 1, 2, 4, 6-30. Voucher: sin muestra colectada.

\section{Desmoncus giganteus A.J.Hend.}

Español: Vara-casha

Usos: Medicinal y cosmético — El tallo es usado con fines medicinales; los frutos son utilizados para tratar enfermedades sanguíneas. Herramientas y utensilios - El tallo se utiliza en la fabricación de asientos, partes de muebles y para canastas; el tallo también sirve como cuerda para atar, por ejemplo, hojas para techo cuando se las transportan del bosque y como tendedero para la ropa; en algunos casos se utilizan los frutos como cebo para la pesca. Para venta - Los tallos son comercializados. Comunidad: 3-14, 16-20, 23-30. Voucher: H. Balslev 7448.

\section{Desmoncus mitis Mart. var. leptospadix (Mart.) A.J.Hend.}

Español: Vara-casha. Urarina: Ucsisi

Usos: Herramientas y utensilios - Se utiliza el tallo en la fabricación de asientos, partes de muebles y para canastas; además el tallo sirve como cuerda para atar por ejemplo hojas para techo cuando se las transportan del bosque y como tendedero para la ropa; en algunos casos se utilizan los frutos como cebo para la pesca. Comunidad: 3-10, 12-14, 16-20, 23-30. Voucher: H. Balslev 6618.

\section{Desmoncus mitis Mart. var. mitis}

Español: Vara-casha. Urarina: Ucsisi

Usos: Herramientas y utensilios - El tallo se utiliza en la fabricación de asientos, partes de muebles y para canastas; el tallo también sirve como cuerda para atar, por ejemplo, hojas para techo cuando se las transportan del bosque y como tende- dero para la ropa; en algunos casos se utilizan los frutos como cebo para la pesca. Comunidad: 3-10, 12-14, 16-20, 23-30. Voucher: H. Balslev 7430 .

\section{Desmoncus mitis Mart. var. tenerrimus (Mart. ex Drude) A.J.Hend.}

Español: Vara-casha. Urarina: Ucsisi

Usos: Herramientas y utensilios - El tallo se utiliza en la fabricación de asientos, partes de muebles y para canastas; el tallo también sirve como cuerda para atar, por ejemplo, hojas para techo cuando se las transportan del bosque y como tendedero para la ropa; en algunos casos se utilizan los frutos como cebo para la pesca. Comunidad: 3, 5-10, 12-14, 16-20, 23-30. Voucher: H. Balslev 6608.

\section{Desmoncus orthacanthos Mart.}

\section{Espańol: Vara-casha}

Usos: Medicinal y cosmético — Una persona reporta que los frutos sirven contra la hepatitis. Herramientas y utensilios - El tallo es empleado en la fabricación de canastos, esteras y asientos; el tallo también sirve como tendedero para la ropa; en algunos casos se utilizan los frutos como cebo para la pesca. Comunidad: 5-9, 12-14, 16-20, 23-27. Voucher: sin muestra colectada.

\section{Desmoncus polyacanthos Mart.}

Español: Vara-casha, Vara casha roja. Urarina: Usisí

Usos: Herramientas y utensilios - El tallo se utiliza en la fabricación de asientos, partes de muebles y para canastas; el tallo también sirve como cuerda para atar, por ejemplo, hojas para techo cuando se las transportan del bosque y como tendedero para la ropa; en algunos casos se utilizan los frutos como cebo para la pesca. Para venta - Los tallos son comercializados. Comunidad: 3, 5-14, 16, 18-20, 23-30. Voucher: H. Balslev 6575.

\section{Elaeis guineensis Jacq.}

Español: Palma africana, Palma aceitera, Palma

Usos: Construcción - Ocasionalmente las hojas son utilizadas en los techos de las viviendas. Alimenticio - Ocasionalmente los frutos maduros son consumidos cocidos; se produce aceite del mesocarpio de los frutos. Para venta - Ocasionalmente el aceite de los frutos es comercializado. Comunidad: 1, 7, 9, 12, 14-16, 18-24, 26, 27, 30. Voucher: sin muestra colectada.

\section{Elaeis oleifera (Kunth) Cortés}

Español: Inayugilla, Puma yarina, Yarinillo. Urarina: Ackidichae

Usos: Medicinaly cosmético — Las hojas de las palmas jóvenes son utilizadas con fines medicinales. Construcción - Algunas veces el tronco es utilizado como madera para la fabricación de paredes en las viviendas; las hojas son utilizadas (entremezcladas con otras de mayor duración) en el techado de las viviendas y cocinas; en algunos casos solo se usan para las cumbreras y para la fabricación de casuchas temporales en el bosque. Herramientasy utensilios - Las hojas sirven para secar pescado; ocasionalmente se utilizan las semillas para artesanías. Alimenticio — Los frutos 
son consumidos por los animales del bosque; ocasionalmente extraen aceite del mesocarpio de los frutos. Comunidad: 1, 4, 6, 10, 13-15, 19-23, 25, 29, 30. Voucher: H. Balslev 7396.

\section{Euterpe catinga Wallace}

Español: Huasaí, Chonta, Chontilla

Usos: Medicinal y cosmético — Las raíces son utilizadas para la elaboración de extractos contra la malaria, hepatitis, fiebre amarilla y pulmonía; los frutos sirven contra la malaria. Herramientas y utensilios - Ocasionalmente el raquis de la inflorescencia es usado como escoba. Comunidad: 1, 2, 6-9, 12, 14-27. Voucher: sin muestra colectada.

\section{Euterpe precatoria Mart.}

Español: Huasaí, Chonta. Urarina: Bueleneé

Usos: Medicinal y cosmético — Las raíces son utilizadas para la elaboración de extractos contra la malaria, hepatitis, fiebre amarilla y dolores estomacales; el extracto de los frutos también es utilizado contra la malaria. Construcción - La madera es utilizada para la fabricación de las paredes, y ocasionalmente los pisos de las viviendas; de manera ocasional los troncos también son utilizados como postes (horcones) en las viviendas y para vigas en la construcción de techos; de forma mas frecuente son utilizados para los cercos de los campos de cultivo o patios; las hojas son utilizadas para el techado de viviendas temporales, o para los bordes de techos y/o cumbas en viviendas permanentes. Herramientas y utensilios - Las hojas tiernas ocasionalmente son utilizadas en la fabricación de abanicos y canastos. Decorativo y religioso - Las hojas jóvenes son utilizadas con fines decorativos en fiestas locales. Alimenticio - Los frutos maduros son cosechados y consumidos crudos y/o cocidos, también son utilizados para la preparación de bebidas y la extracción de aceite; el palmito es comestible y uno de los mas apetecidos, las larvas de coleóptero (suris) que ocasionalmente se desarrollan en los troncos viejos caídos son cosechadas y consumidas cocidas; las flores son consumidas en alimentos y bebidas. Para venta - Ocasionalmente el palmito es comercializado ( 0,5 soles/palmito); los frutos se comercializan para la elaboración de refrescos. Comunidad: 1-30. Voucher: H. Balslev 6623.

\section{Geonoma arundinacea Mart.}

Español: Ponilla. Urarina: Cajiaguí

Usos: Herramientas y utensilios - Los tallos son utilizados como soporte (timbina) para instalar los mosquiteros y para la fabricación de lanzas utilizadas para la pescar. Comunidad: 1, 3 (transectos), 6, 12, 14, 15, 20, 22, 24, 25. Voucher: $H$. Balslev 6585.

\section{Geonoma atrovirens Borchs. \& Balslev}

Español: Calzón panga

Usos: Construcción - No es muy común pero en algunos casos usan las hojas para techos. Herramientas y utensilios — Las hojas tiernas ocasionalmente son utilizadas en canastos de rápida fabricación. Alimenticio — Las hojas sirven para envolver pescado y otros alimentos Comunidad: 2, 7, 9, 12, 13, 20, 22-25. Voucher: H. Balslev 7405 .

\section{Geonoma brongniartii Mart.}

Español: Ponilla, Palmiche

Usos: Medicinal y cosmético - Su flor tiene un fragancia muy agradable y sirve como perfume. Construcción - Las hojas se utilizan en los techos de las viviendas. Comunidad: 3, 5, 7, 9, 10, 12, 13, 15-17, 19-30. Voucher: H. Balslev 6606.

\section{Geonoma camana Trail}

Español: Bijou de la altura, Palmiche, Chondilla, Shapajillo. Urarina: Caneé

Usos: Construcción - En algunas partes se utilizan las hojas para los techos de las viviendas. Para venta - Ocasionalmente las hojas son comercializadas para la fabricación de techos. Comunidad: $3,5,10-12,14-16,19,21,23,28-30$. Voucher: H. Balslev 7437.

\section{Geonoma deversa (Poit.) Kunth}

Español: Palmiche, Ponilla

Usos: Construcción — Las hojas son utilizadas en la construcción de los techos para las viviendas. Herramientas y utensilios - En pocos casos se utiliza la raíz como escoba. Comunidad: 4, 7, 9, 12-16, 18-21, 23-26. Voucher: H. Balslev 7513.

\section{Geonoma leptospadix Trail}

Español: Ponilla, Palmiche

Usos: Construcción — Las hojas son utilizadas en la construcción de los techos para las viviendas. Herramientas y utensilios - En pocos casos se utiliza la raíz como escoba. Comunidad: 4, 7, 9, 13-15, 18, 20, 21, 23-26. Voucher: H. Balslev 7533.

\section{Geonoma macrostachys Mart. var. acaulis (Mart.) A.J.Hend.}

Espańol: Yarinilla, Palmiche, Ponilla

Usos: Medicinal y cosmético — La raíz es utilizada para el cuidado del cabello; utilizan un cocimiento de las hojas para bañarse; las flores sirven contra la fiebre y vómitos. Construcción - Ocasionalmente las hojas son utilizadas en la construcción de los techos para las viviendas. Comunidad: 3, 5, 10, 11, 14, 15, 19, 21, 26-30. Voucher: H. Balslev 6590.

\section{Geonoma macrostachys Mart. var. macros- tachys}

Español: Calzón panga

Usos: Medicinal y cosmético — Una infusión de los pecíolos es utilizada para aliviar dolores menstruales. Construcción Ocasionalmente las hojas son utilizadas en la construcción de los techos para las viviendas. Alimenticio - Ocasionalmente se utilizan las hojas para envolver pescado. Comunidad: 7, 11, 12, 24. Voucher: H. Balslev 7099.

\section{Geonoma maxima (Poit.) Kunth var. chelidonura} (Spruce) A.J.Hend.

Español: Palmiche, Ponilla 
Usos: Construcción — Las hojas son utilizadas en la construcción de los techos para las viviendas; se utiliza el tallo para la fabricación de cercas. Herramientas y utensilios - Una persona dice que los frutos sirven como las bolas adentro del sonajero para niños. Alimenticio - Ek fruto es comestible, pero este uso no es muy común. Comunidad: 1, 7, 13-16, 19, 21, 23-27. Voucher: H. Balslev 7458 .

\section{Geonoma poeppigiana Mart.}

\section{Español: Palmiche}

Usos: Construcción — Las hojas son ampliamente utilizadas para la construcción de los techos de las viviendas. Comunidad: 1 , 4, 7, 9, 12, 14, 16, 19-21, 23-27. Voucher: H. Balslev 7263.

\section{Geonoma stricta (Poit.) Kunth}

Español: Barigito Ponilla, Palmiche. Urarina: Ajcanadijií

Usos: Construcción — Ocasionalmente las hojas son utilizadas en la construcción de los techos para las viviendas. Herramientas y utensilios - Los frutos se utilizan como balas para matar aves o dentro de sonajeros para niños, pero no es muy común. Comunidad: $1,3-5,7,10,12,14,15,16,17,19-21,23-25$, 28-30. Voucher: H. Balslev 6638.

\section{Hyospathe elegans Mart.}

Espańol: Ponilla, Saapap, Palmiche

Usos: Medicinal y cosmético — La raíz es utilizada contra las náuseas, vómitos y dolores de la cabeza; las flores son buenas para dolores de estómago. Construcción - Las hojas son utilizadas en la construcción de los techos para las viviendas; a veces el tallo también en partes de techos (crisnejas). Herramientas y utensilios - Los tallos son utilizados como soporte (timbina) para instalar los mosquiteros; las hojas se pueden usar como flauta. Alimenticio - Ocasionalmente los frutos son consumidos. Comunidad: 3, 4, 7, 11-13, 16, 19, 24, 25, 27, 29. Voucher: H. Balslev 6548.

\section{Iriartea deltoidea Ruiz \& Pav.}

Español: Pona, Huacrapona. Urarina: Atanaje, Adanaí

Usos: Medicinal y cosmético — Las raíces son ocasionalmente utilizadas con fines medicinales contra la hepatitis. Construcción — La madera obtenida del tronco, es utilizada para los pisos y las paredes de las viviendas; menos frecuente es el uso de los troncos para postes (horcones) en las viviendas, las vigas de los techos (rippas) y pisos, y como postes en los campos de cultivo; las hojas son utilizadas para el techado de casuchas temporales. Herramientas y utensilios - Las hojas son empleadas en la fabricación rápida de canastos para el traslado de frutos, o animales muertos cuando acuden al bosque en busca de ellos; ocasionalmente las hojas son utlizadas para secar pescado o como envoltorio para la cocción de otros alimentos; la madera del tronco es utilizada para la fabricación de dardos; ocasionalmente las raíces fúlcreas son cortadas para ser utilizadas como rallador. Decorativo y religioso - Ocasionalmente las hojas son utilizadas con fines decorativos en ceremonias religiosas o eventos festivos. Alimenticio - En muy baja escala los frutos son consumidos y utilizados para la elaboración de bebidas; el palmito es comestible; las larvas que se desarrollan en los troncos caídos son cosechadas y consumidas cocidas. Comunidad:1-10, 12-30. Voucher: H. Balslev 6636.

\section{Iriartella stenocarpa Burret}

Español: Camonilla, Casha ponita, Pona, Ponilla, Cashapona, Huacrapona, Wacra pona

Usos: Medicinal y cosmético - El extracto de la raíz es ocasionalmente utilizado contra la hepatitis, malaria y tuberculosis. Construcción - El tallo es utilizado para las vigas de los techos, pisos y otras partes de las viviendas; ocasionalmente las hojas son utilizadas en la construcción de los techos para las viviendas. Herramientas y utensilios — La raíz sirve como rallador de plátanos y otros tipos de alimentos. Alimenticio - Se utilizan las hojas para envolver pescado. Comunidad: 1, 4, 6, 7, 9, 11-17, 19-28. Voucher: H. Balslev 7280.

\section{Itaya amicorum H.E.Moore}

Español: Bombonaje, Falso bombonaje, Sacha bombonaje

Usos: Construcción — Las hojas son utilizadas en la construcción de los techos para las viviendas. Herramientas y utensilios Se hacen sombreros de las hojas. Alimenticio — Ocasionalmente los frutos maduros son consumidos. Comunidad: 2, 6, 7, 9, 12 , 13, 15-17, 19-26. Voucher: sin muestra colectada.

\section{Lepidocaryum tenue Mart.}

\section{Español: Irapay}

Usos: Medicinal y cosmético — Las raíces sirven contra el dolor de cabeza, la garganta, y contra la malaria; los frutos se utilizan para curar la piel seca y la fiebre. Construcción - Las hojas son ampliamente utilizadas en el techado de las viviendas. Herramientas y utensilios - Las semillas se usan para collares. Alimenticio - Ocasionalmente los frutos maduros son consumidos. Para venta - Las hojas son vendidas a empresas pequeñas o utilizadas para la fabricación de "crisnejas" (partes de techo) para la venta directa. Comunidad: $1-4,6-16,19-30$. Voucher: H. Balslev 7337.

\section{Mauritia carana Wallace ex Archer}

Español: Aguaje, Aguaje del barrial

Usos: Construcción - El tronco ocasionalmente es utilizado para postes (horcones) en las viviendas; las hojas son utilizadas en la construcción de los techos para las viviendas. Alimenticio - Los frutos maduros son comestibles en algunas partes; las larvas de coleóptero (suri) que se desarrollan en los troncos caídos son consumidas cocidas. Comunidad: 7, 12. Voucher: sin muestra colectada.

\section{Mauritia flexuosa L.f.}

\section{Espańol: Aguaje. Urarina: Alaá}

Usos: Medicinal y cosmético — La raíz es utilizada contra la hepatitis y los frutos maduros se utilizan con fines medicinales; el cataplasma de las raíces es colocado en el pecho de las mujeres para ayudar en la producción de leche; las flores son utilizadas contra los dolores de cabeza; los frutos son utilizados contra la 
malaria. Construcción - El tronco ocasionalmente es utilizado para postes (horcones) en las viviendas y campos de cultivo, también para vigas en la construcción de los techos, escaleras, pisos y paredes; la hojas son utilizadas en el techado de las cocinas y viviendas temporales; ocasionalmente con los pecíolos se fabrican las paredes de viviendas temporales. Herramientas y utensilios - El tronco ocasionalmente es utilizado para la fabricación de canoas y balsas, y como madera en la fabricación de puentes; de la médula de los pecíolos se hacen colchones muy suaves y ventilados; las hojas tiernas son utilizadas para la obtención de fibras que son empleadas para fabricar abanicos, canastos, sombreros y ropa tradicional (como faldas de rafia); las hojas secas son usadas para sellar roturas en las canoas. Alimenticio - Los frutos maduros son comestibles crudos y/o cocidos, y utilizados para la elaboración de bebidas (chicha), helados o mermeladas; el palmito es comestible; las larvas de coleóptero (suri) que se desarrollan en los troncos caídos son consumidas cocidas; las raíces fúlcreas cocidas son consumidas; las flores son ocasionalmente consumidas. Para venta — Los frutos maduros son comercializados (5-8 soles/50 k); las raíces fúlcreas son también comercializadas. Comunidad:1-30. Voucher: H. Balslev 7395.

\section{Mauritiella armata (Mart.) Burret}

Español: Aguajillo. Urarina: Agueé

Usos: Construcción - El tronco es utilizado para los postes (horcones) de las viviendas y en los cercos de campos de cultivo y patios; ocasionalmente la madera es utilizada para las paredes de las viviendas; las hojas son utilizadas en la construcción de los techos para las viviendas temporales y cocinas. Alimenticio - Los frutos maduros son comestibles cocidos y utilizados en la preparación de bebidas; ocasionalmente el palmito es consumido. Comunidad: $1-4,6-9,12-16,18-30$. Voucher: H. Balslev 7371.

\section{Oenocarpus bataua Mart.}

Español: Unguragui, Siname, Hungurahui: Urarina: Acué

Usos: Medicinal y cosmético — Las raíces y el palmito son utilizados para la elaboración de un extracto utilizado como tratamiento contra la hepatitis, la fiebre y la malaria; un extracto de las raíces es usado contra la fiebre amarilla y pulmonía; la bebida obtenida de la cocción de los frutos es utilizada contra la malaria, dolor de estómago y afecciones respiratorias; las semillas son usadas para tratar casos de diarrea; el aceite extraído de las semillas es utilizado con fines cosméticos para aplicarlo en el cabello. Construcción Los troncos son utilizados para postes (horcones), vigas de techos y pisos, y como madera para pisos y paredes en la construcción de las viviendas; las hojas son utilizadas en el techado de las viviendas permanentes y temporales, y de forma particular para las cumbas. Herramientas y utensilios - Las hojas jóvenes son utilizadas para la fabricación rápida de canastos en el bosque; las inflorescencias y las fibras de las hojas son utilizadas para la fabricación de escobas. Decorativo y religioso - Durante el carnaval se utiliza la palma como decorativo; las flores sirven como decorativo también. Alimenticio - El fruto maduro es comestible y cocido utilizado para la preparación de bebidas (similar a la leche); el palmito es comestible; las larvas de coleóptero (suri) que se desarrollan en sus troncos viejos son comestibles; ocasionalmente cuando los frutos y las semillas son hervidos se puede extraer aceite. Para venta - Ocasionalmente las larvas cosechadas de los troncos son comercializadas; los troncos se venden para construcción; las fibras de las hojas se venden en algunos casos. Comunidad: 1-16, 18-30. Voucher: H. Balslev 7374.

\section{Oenocarpus mapora H. Karst.}

Español: Sinamillo/a, Sinami, Siyamba, (Siamba), Bacabilla. Urarina: Naaé, Imaá

Usos: Medicinal y cosmético — Las raíces son extraídas para la preparación de medicamentos contra la hepatitis, la tos, la malaria y la diarrea; ocasionalmente las raíces son utilizadas como shampoo; las vainas se utilizan como compresa contra el dolor de espalda; los frutos son utilizados contra la malaria, la tos y el dolor de estómago. Construcción - Los troncos son utilizados como postes (horcones), y como madera para pisos y paredes en la construcción de la viviendas; las hojas ocasionalmente utilizadas para el techado de viviendas. Herramientas y utensilios — Las hojas jóvenes son utilizadas para la fabricación rápida de canastos en el bosque; el raquis de la inflorescencia ocasionalmente es usado como cepillo. Decorativo y religioso - En la época de carnaval se utiliza toda la planta como decorativo, se ponen regalos en la copa y dan golpes al tronco hasta que caen los regalos. Alimenticio - Frutos maduros comestibles cocidos y utilizados para la preparación de bebidas; pocos extraían el aceite; el palmito es comestible. Comunidad:1-30. Voucher: H. Balslev 7528.

\section{Pholidostachys synanthera (Mart.) H.E.Moore}

\section{Español: Palmiche}

Usos: Construcción - las hojas son utilizadas en la construcción de los techos para las viviendas. Alimenticio - Ocasionalmente los frutos maduros y el palmito son consumidos. Comunidad: 7, 9, 12-16, 19-21, 23-27, 29, 30. Voucher: H. Balslev 7452 .

\section{Phytelephas tenuicaulis (Barfod) A.J.Hend.}

Español: Yarina, Tagua. Urarina: Acanií

Usos: Medicinal y cosmético — El palmito es utilizado para la obtención de extractos contra la hepatitis y malaria; los frutos verdes son utilizados contra dolor en el bajo vientre, la fiebre y problemas de la piel. Construcción - Las hojas son utilizadas en la construcción de los techos para las viviendas permanentes (duración 3-4 años), temporales (tambos) y en los bordes o chumberas de techos fabricados con hojas de otras palmas; los troncos son ocasionalmente utilizados para los postes (horcones) de las viviendas pequeńas y para cercos en campos de cultivo. Herramientas y utensilios - Antiguamente se usaban las semillas para hacer botones de ropa. Alimenticio - Los frutos maduros son consumidos crudos o se consume el líquido; ocasionalmente el palmito y las semillas aun inmaduras son recolectados para ser consumidos; de forma ocasional las flores son consumidas. Para venta - Las semillas ocasionalmente son comercializadas para la fabricación de artesanías. Comunidad: 1-4, 6-30. Voucher: H. Balslev 7107.

\section{Prestoea schultzeana (Burret) H.E.Moore}

Espańol: "un tipo de Unguragui" 
Usos: Construcción — Las hojas son ocasionalmente utilizadas para la fabricación de casuchas temporales. Alimenticio - Ocasionalmente los frutos maduros son consumidos. Comunidad: 3 (transecto), 12, 13, 16, 19, 22, 23, 26. Voucher: H. Balslev 6603.

\section{Socratea exorrhiza (Mart.) H. Wendl.}

Español: Casha pona, Paschi, Tarapoto, Wacra pona, Pona. Urarina: Eichú

Usos: Medicinal y cosmético — Las raíces y el palmito son utilizadas para la obtención de un extracto que es usado contra la hepatitis, náusea y vómito. Construcción - Los troncos son utilizados para obtener tablas que son usadas en los pisos y las paredes de las viviendas, y como vigas en la construcción de techos; ocasionalmente también son usados como postes en la construcción de viviendas y cercos; las hojas son ocasionalmente utilizadas en el techado de viviendas temporales y viviendas chicas. Herramientas y utensilios - Ocasionalmente las raíces fúlcreas cubiertas de espinas son utilizadas para rallar plátano o pelar yuca; las semillas se utilizan para collares. Alimenticio Los frutos suelen ser utilizados para la elaboración de bebidas y se comen; las larvas de coleóptero que se desarrollan en los

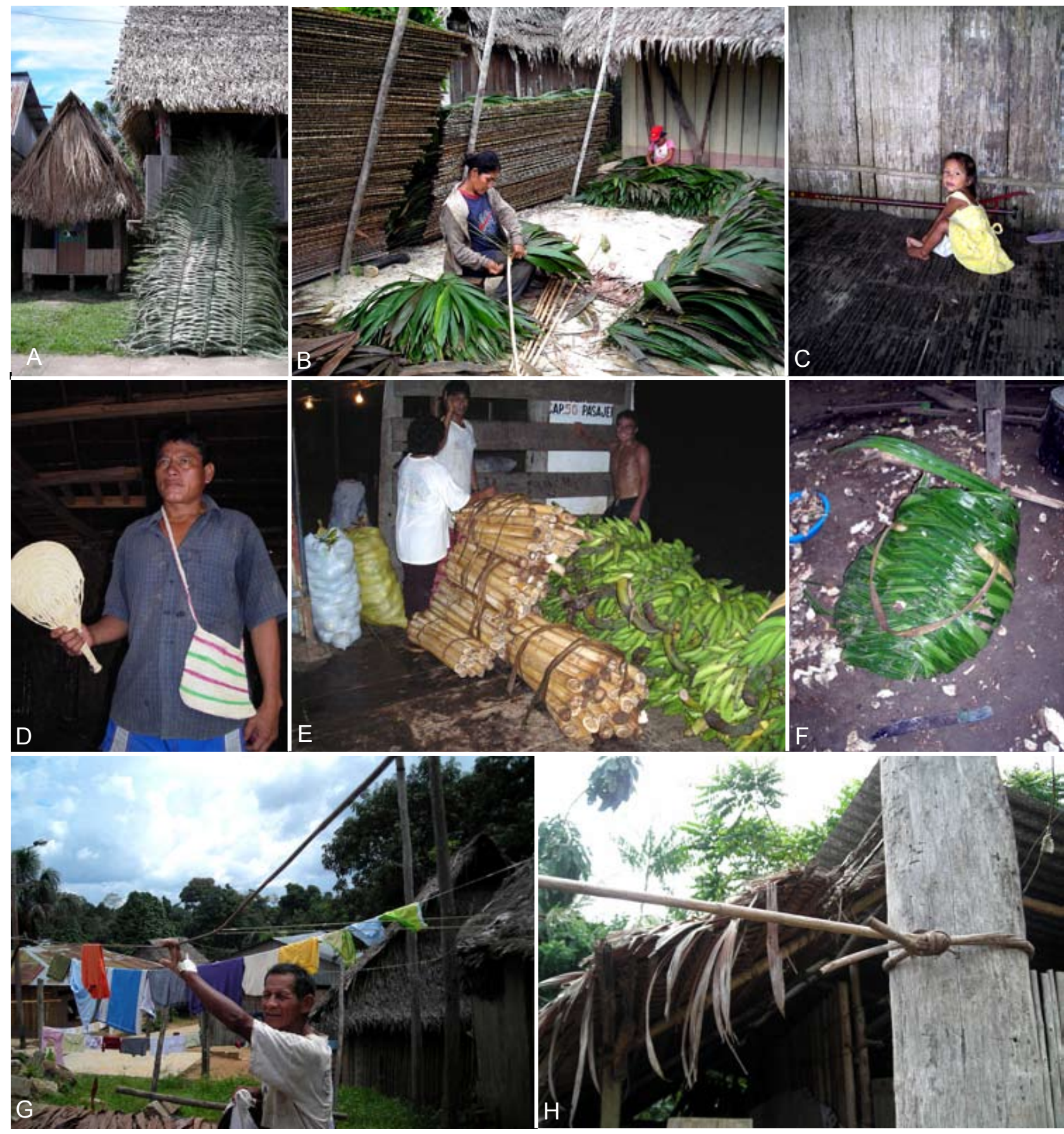

Figura 2. Usos de palmeras, en los alrededores de Iquitos, Amazonía Peruana. A. Techos de Mauritia flexuosa (vivienda pequeña lado izquierdo) y de Attalea phalerata (vivienda grande lado derecho), y cumbreras aún no colocadas (hojas verdes de Attalea phalerata apoyadas). B. Hojas de Lepidocaryum tenue, tejidos para la construcción de los techos. C. Interior de vivienda rústica con pisos y paredes utilizando madera de Socratea exorrhiza. D. Abanico tejido de hojas de Astrocaryum chambira. E. Palmitos de Euterpe precatoria siendo transportado a los mercados en Iquitos. F. Canasto tejido de hojas de Aphandra natalia. G-H. Tallo de Desmoncus giganteus usado como cuerda. 
troncos caídos suelen ser colectadas y consumidas cocidas; ocasionalmente se extrae aceite de los frutos hervidos; el palmito es comestible. Comunidad: 1-4, 6-30. Voucher: H. Balslev 7332 .

\section{Wettinia augusta Poepp. \& Endl.}

Español: Ponilla

Usos: Construcción - El tronco ocasionalmente es utilizado para construcción de las viviendas; muy pocos utilizan la hojas para el techado de viviendas. Comunidad: $6,7,9,12,13,15$, 16, 19, 20, 23-27. Voucher: H. Balslev 7355.

\section{Wettinia drudei (O.F.Cook \& Doyle) A.J.Hend.}

Español: Ponilla

Usos: Construcción - El tallo ocasionalmente es utilizado para construcción de viviendas. Comunidad: 1, 6, 7, 9, 12, 15, 16, 19, 21, 23-27. Voucher: H. Balslev 7102.

\section{Agradecimientos}

Agradecemos el apoyo económico del Danish Natural Science Research Council (272-06-0476), de Danida (104.Dan.8-764) y de WWF/Novozymes Research Grant.

\section{Literatura citada}

Bjorholm S., J.-C. Svenning, F.Skov \& H. Balslev. 2005. Environmental and spatial controls of palm (Arecaceae) species richness across the Americas. Global Ecology and Biogeography 14: 423-429.

Bodmer R.E., P.E. Puertas, J.E. García, D.R. Dias \& C. Reyes. 1999. Game animals, palms, and people of the flooded forests: Management considerations for the Pacaya-Samiria national reserve, Peru. Advances in Economic Botany 13: 217-231.

Borchsenius F., H. Balslev \& J.-C. Svenning. 2001. Two new species of Geonoma sect. Taenianthera (Arecaceae) from the western Amazon. Nordic Journal of Botany 21: 341-348.

Goulding M. 1980. The Fishes and the Forest. Explorations in Amazonian Natural History. University of California Press, Berkeley.

Govaerts R. \& J. Dransfield. 2005. World Checklist of Palms. Royal Botanic Gardens, Kew, UK.

Henderson A. 1995. The Palms of the Amazon. Oxford UP., New York, Oxford.

Henderson A. 2000. Bactris (Palmae). Flora Neotropica Monographs 79: $1-181$.

Henderson A. \& F. Chavez. 1993. Desmoncus as a useful palm in the western Amazon. Principes 34: 184-186.

Henderson A., G. Galeano \& R. Bernal. 1995. Field Guide to the Palms of the Americas. Princeton UP., Princeton, New Jersey.

Hiraoka M. 1985. Floodplain farming in the Peruvian Amazon. Geogr. Rev. Japan 58, ser. B, no. 1: 1-23.

Hübschmann L., L.P. Kvist, C. Grandez \& H. Balslev, 2007. Uses of vara casha, a neotropical liana palm - Desmoncus polyacanthos - in Iquitos, Peru. Palms 51: 167-176.

Kahn F. 1988. Ecology of economically important palms in Peruvian Amazonia. Advances in Economic Botany 6: 42-49.

Kahn F. 1991. Palms as a key swamp forest resource in Amazonia. Forest Ecology and Management 1991: 133-142.
Kahn F. 2008. The genus Astrocaryum (Arecaceaae). Rev. peru. biol. 15(supl. 1): 031-048.

Kahn F. \& K. Mejía, 1987. Notes on the biology, ecology, and use of a small Amazonian palm: Lepidocaryum tessmannii. Principes 31: 215-219.

Kahn F. \& K. Mejia. 1990. Palm communities in wetland forest ecosystems of Peruvian Amazonia. Forest Ecology and Management 33/34: 169-179.

Kahn F., K. Mejía, F. Moussa \& D. Gómez, 1993. Mauritia flexuosa, la más acuática de la palmeras amazónicas. Pp. 287-308 En: Kahn, F., León, B. \& Young, K. (Eds.), Las plantas vasculares en las aguas continentales del Perú. IFEA, Lima.

Kahn F. \& B. Millan. 1992. Astrocaryum (Palmae) in Amazonia. A preliminary treatment. Bull. Inst. Fr. Ét. And. 21(2): 459-531

López Parodi J. 1988. The use of palms and other native plants in non-conventional, low cost rural housing in the Peruvian Amazon. Advances in Economic Botany 6: 119-129.

Macía M. J. \& J.-C. Svenning. 2005. Oliogarchic dominance in western Amazonian plant communities. Journal of Tropical Ecology 21: 613-626.

Mejía K. 1988. Utilization of palms in eleven Mestizo villages of the Peruvian Amazon (Ucayali River, Department of Loreto). Advances in Economic Botany 6: 130-136.

Mejía, K. 1992. Las palmeras en los mercados de Iquitos. Bull. Inst. Fr. Ét. And. 21(2): 755-769.

Montúfar, R. \& J.-C. Pintaud. 2006 Variation in species composition, abundance and microhabitat preferences among western Amazonian terra firme palm communities. The Botanical Journal of the Linnean society 151: 127-140.

Padoch C. 1988. Aguaje (Mauritia flexuosa L.f.) in the economy of Iquitos, Peru. Advances in Economic Botany 6: 214-224.

Padoch C. \& W. de Jong, 1990. Santa Rosa: the impact of the forest products trade on an Amazonian place and population. Advances in Economic Botany 8: 151-158.

Paniagua Zambrana N.Y., A. Byg, J.-C. Svenning, M. Moraes, C. Grandez \& H. Balslev. 2007. Diversity of palm uses in the western Amazon. Biodiversity and Conservation 16: 2771-2787.

Peters C., M.J. Balick, F. Kahn, \& A.B. Anderson. 1989. Oligarchic forests of economic plants in Amazonia: Utilization and conservation of an important tropical resource. Conservation Biology 3: 341-349.

Peters C.M. \& E.J. Hammond. 1990. Fruits from the flooded forests of Peruvian Amazonia: Yield estimates for natural populations of three promising species. Advances in Economic Botany 8: 159-176.

Puhakka M. \& R.Kalliola. 1993. La vegetación de áreas de inundación en la selva baja de la Amazonia peruana. Pp. 113-138 En: Kalliola, R., Puhakka, M. \& Danjoy, W.. (Eds.), Amazonia Peruana. Vegetación Húmeda Tropical en el Llano Subandino. Universidad de Turku, Finlan

Vargas V., \& J.-C. Pintaud. 2008. Caracterización de una zona de contacto parapátrico entre Astrocaryum macrocalyx y Astrocaryum urostachys en el límite entre la planicie Marañón-Pastaza y el Arco de Iquitos. Rev. peru. biol. 15(supl. 1): 079- 083

Vormisto J., J.-C. Svenning, P. Hall \& H. Balslev. 2004. Diversity and dominance in palm (Arecaceae) communities in the western Amazon basin. Journal of Ecology 92: 577-588.

Zona S. 2002. Name changes in Attalea. Palms 46: 132-133. 